\title{
Body Mass Index and Retinopathy in Type 1 Diabetic Patients
}

\author{
Snježana Kaštelan, ${ }^{1}$ Jasminka Salopek Rabatić, ${ }^{1}$ Martina Tomić, ${ }^{2}$ \\ Antonela Gverović Antunica, ${ }^{3}$ Spomenka Ljubić, ${ }^{4}$ Helena Kaštelan, ${ }^{3}$ \\ Branko Novak, ${ }^{4}$ and Darko Orešković ${ }^{5}$ \\ ${ }^{1}$ Department of Ophthalmology, Clinical Hospital Dubrava, Avenija Gojka Šuška 6, 10000 Zagreb, Croatia \\ ${ }^{2}$ Department of Ophthalmology, University Clinic Vuk Vrhovac, Clinical Hospital Merkur, Zajčeva 19, 10000 Zagreb, Croatia \\ ${ }^{3}$ Department of Ophthalmology, General Hospital Dubrovnik, Dr. Roka Mišetića 2, 20000 Dubrovnik, Croatia \\ ${ }^{4}$ Department of Endocrinology and Metabolic Diseases, University Clinic Vuk Vrhovac, Clinical Hospital Merkur, Zajčeva 19, \\ 10000 Zagreb, Croatia \\ ${ }^{5}$ University of Zagreb, School of Medicine, Šalata 3b, 10000 Zagreb, Croatia
}

Correspondence should be addressed to Snježana Kaštelan; snjezanakastelan@yahoo.com

Received 25 October 2013; Revised 19 December 2013; Accepted 2 January 2014; Published 18 February 2014

Academic Editor: Durga N. Tripathi

Copyright (C) 2014 Snježana Kaštelan et al. This is an open access article distributed under the Creative Commons Attribution License, which permits unrestricted use, distribution, and reproduction in any medium, provided the original work is properly cited.

\begin{abstract}
Aim. To investigate whether body mass index (BMI) independently or in correlation with other risk factors is associated with diabetic retinopathy (DR) progression. Methods. The study included 176 patients with type 1 diabetes divided into three groups according to DR status: group 1 (no retinopathy; $n=86$ ), group 2 (mild/moderate nonproliferative DR; $n=33$ ), and group 3 (severe/very severe NPDR or proliferative DR; $n=57$ ). Results. A significant deterioration of $\mathrm{HbA}_{1} \mathrm{c}$, an increase in total cholesterol, systolic, diastolic blood pressure, and diabetic nephropathy with the progression of retinopathy were found. DR progression was correlated with diabetes duration, $\mathrm{HbA}_{1} \mathrm{c}$, hypertension, total cholesterol, and the presence of nephropathy. In patients without nephropathy, statistical analyses showed that progression of retinopathy increased significantly with higher BMI (gr. 1: $24.03 \pm 3.52$, gr. 2: $25.36 \pm 3.44$, gr. 3: $26.93 \pm 3.24 ; P<0.01$ ). A positive correlation between $B M I$ and a significant deterioration of $\mathrm{HbA}_{1} \mathrm{c}$, an increase in cholesterol, triglycerides, and hypertension was observed. Conclusion. BMI in correlation with $\mathrm{Hb}_{1} \mathrm{c}$, cholesterol, and hypertension appears to be associated with the progression of DR in type 1 diabetic patients without nephropathy. However, additional studies are required to investigate the pathogenic role of obesity and weight loss in retinal diabetic complications particularly relating to nephropathy.
\end{abstract}

\section{Introduction}

Diabetes mellitus is the most frequent endocrine disease in developed countries estimated to have affected 366 million people worldwide and is expected to nearly double by 2030 . This growing trend is observed for both type 2 and type 1 diabetes where type 1 accounts for $5-10 \%$ of the total cases and its increased incidence is seen across the world in various population studies with the range between $2 \%$ and 5\% [1-4]. Type 1 diabetes is an autoimmune disease mediated by a combination of genetic and environmental triggers, however, its increasing incidence worldwide cannot be explained by genetic factor alone. Recent studies suggest an alternative possible cause of this epidemic, namely, the role of infections, early childhood diet, environmental pollutants, insulin resistance, and obesity [4].

The global increase of diabetes has a significant impact on the prevalence of diabetic complications among which diabetic retinopathy (DR) takes an important place $[5,6]$. $\mathrm{DR}$ is a leading cause of acquired blindness in workingage adults and has been estimated to represent $12 \%$ of blindness in developed countries $[7,8]$. The prevalence of retinopathy increases with the duration of diabetes and is related to hyperglycemia, hypertension, hyperlipidemia, pregnancy, nephropathy, and anemia with genetic factors also having a specific role [9-17]. DR is characterized by the loss of pericytes, hypertrophy of the basement membrane, microaneurysm formation, increased vascular permeability, 
capillary occlusions, neovascularization, and fibrovascular proliferation. The predominant cause of visual loss in diabetic patients results primarily from intraocular angiogenesis (proliferative diabetic retinopathy, PDR) and leakage of the retinal vessels (diabetic macular edema, DME) [7, 13].

Since DR has become a main cause of vision loss and blindness worldwide intense focus on the early prevention of DR and the benefit of controlling modifiable risk factors has become increasingly important. Although numerous studies have confirmed the role and importance of established risk factors for the development and progression of DR [9, 10], the evidence from new recent trials have nonetheless shown that risk reduction for DR with better glucose and blood pressure management has its limits [18, 19]. Thus, a better comprehension of the role of other modifiable risk factors including obesity in the development of DR becomes even more valuable. The evidence supporting a relationship between high body mass index (BMI) and increased risk of DR is inconclusive [20-33]. Some studies have demonstrated a relationship between obesity or higher BMI and an increased risk of DR [20, 22-29] whilst others have yielded conflicting results [30-33].

Considering that obesity is becoming increasingly prevalent in today's society and since it can be managed by lifestyle intervention particularly exercise, nutrition, and education, studying its effect on diabetic complications has certain logic and benefits. Thus the aim of the present study was to investigate whether obesity independently or in association with other established risk factors influences DR development in type 1 diabetic patients.

\section{Patients and Methods}

This cross-sectional study was performed in collaboration with the Ophthalmology Departments of three Croatian Hospitals in accordance with the Declaration of Helsinki and approved by the Ethics Committee of each Hospital. The patients included in the study received both written and oral information concerning the study and signed a written informed consent.

2.1. Patients. A total of 176 patients with type 1 diabetes were included in the study. All of them were on insulin therapy. Type 1 diabetes was defined according to the American Diabetes Association classification [2]. Patients with immunologic, infectious or inflammatory diseases, and malignancies as well as those taking cytostatics or corticosteroids, pregnant women, and patients with other eye diseases (mature cataract, uveitis, age-related macular degeneration) were not included in the study.

2.2. Methods. This study consisted of patients with diabetes who underwent their regular medical and ophthalmological checkups during a one-year period. All patients who met the inclusion criteria were invited to partake in the study and signed the consent form. Blood samples for laboratory analyses were collected between 08:00 and 10:00 am after a 12-hour overnight fast and complete clinical and ophthalmic examinations were done.

2.2.1. Blood Samples. Glycated hemoglobin value $\left(\mathrm{HbA}_{1} \mathrm{c}\right)$, total cholesterol, triglycerides, and HDL cholesterol were measured. $\mathrm{HbA}_{1} \mathrm{c}$ was determined by an automated immunoturbidimetric assay (reference values 3.5-5.7\%) [34]. Total cholesterol, triglycerides, and HDL cholesterol were measured by the enzymatic colorimetric tests (reference values: total cholesterol $<5.00 \mathrm{mmol} / \mathrm{L}$; triglycerides $<1.70 \mathrm{mmol} / \mathrm{L}$; HDL cholesterol $>1.0 \mathrm{mmol} / \mathrm{L})[35,36]$.

2.2.2. Anthropometric Parameters. BMI was calculated by dividing weight and height squared $\left(\mathrm{kg} / \mathrm{m}^{2}\right)$. A balancebeam scale was used to measure weight, and height was measured using a wall-mounted stadiometer with patients in their underwear and without shoes. Recommended value of BMI among men was considered $<23$ and among women $<22 \mathrm{~kg} / \mathrm{m}^{2}$ with a normal range being between 18.5 and $24.9 \mathrm{~kg} / \mathrm{m}^{2}$ [37].

2.2.3. Clinical Parameters. Blood pressure was measured with an ambulatory sphygmomanometric device after a $5 \mathrm{~min}$ rest and the mean of three measurements was used. All three measurements were conducted during the same visit. Hypertension was defined as blood pressure $>130 / 80 \mathrm{mmHg}$ or the use of antihypertensive treatment.

2.2.4. Ophthalmologic Examination. Complete eye examination included best corrected visual acuity (BCVA), Goldmann applanation tonometry, slit lamp biomicroscopy of the anterior eye segment, binocular indirect slit lamp fundoscopy, and fundus photography after mydriasis with topically administrated $1 \%$ tropicamide and 5\% phenylephrine eye drops. Color fundus photographs of two fields: macular field and disc/nasal field of both eyes were taken using a $45^{\circ}$ fundus camera (VISUCAM, Zeiss) according to the Europe and Diabetes Study (EURODIAB) retinal photography methodology [38]. Macular field: where the exact centre of the optic disc is laid at the nasal end of the horizontal meridian of the field view. Disc/nasal field: where the optic disc is positioned one disc-diameter in from the temporal edge of the field on the horizontal meridian. The EURODIAB classification scheme was applied since it uses two-field $45^{\circ}$ fundus photography and standard photographs to grade retinal lesions [38]. Patients were divided into three groups according to the DR status: group 1 (no retinopathy; $n=86$ ), group 2 (mild/moderate nonproliferative DR (NPDR); $n=$ 33), and group 3 (severe/very severe NPDR or proliferative diabetic retinopathy (PDR); $n=57)$. The status of the seriously affected eye was the basis on which severity of retinopathy was determined.

2.2.5. Diabetic Nephropathy. Diabetic nephropathy has been categorized and classified into stages based on the values of urinary albumin excretion (UAE): microalbuminuria and macroalbuminuria [39]. 
TABLE 1: Basic characteristics of type 1 diabetic patients $(n=176)$ divided into three groups according to diabetic retinopathy status.

\begin{tabular}{|c|c|c|c|c|}
\hline & $\begin{array}{l}\text { Group 1 } \\
(n=86)\end{array}$ & $\begin{array}{l}\text { Group 2 } \\
(n=33)\end{array}$ & $\begin{array}{l}\text { Group } 3 \\
(n=57)\end{array}$ & $P$ \\
\hline $\operatorname{Sex}(m / f)^{* *}$ & $46.51 / 53.49$ & $54.55 / 45.45$ & $53.14 / 43.86$ & ns \\
\hline Age (years) ${ }^{*}$ & $37.19 \pm 16.62$ & $45.06 \pm 12.56$ & $41.40 \pm 11.23$ & $<0.05$ \\
\hline $\begin{array}{l}\text { Diabetes } \\
\text { duration } \\
\text { (years) }^{*}\end{array}$ & $12.94 \pm 6.77$ & $23.03 \pm 8.94$ & $24.67 \pm 7.20$ & $<0.01$ \\
\hline
\end{tabular}

${ }^{*}$ mean $\pm \mathrm{SD}^{* *} \%$; percentage.

Group 1: no retinopathy, group 2: mild/moderate nonproliferative diabetic retinopathy; group 3: severe/very severe nonproliferative diabetic retinopathy or proliferative diabetic retinopathy.

2.3. Statistical Analyses. Descriptive statistics ( $n$, mean \pm standard deviation) for all analyzed variables were conducted. Differences in distributions of continuous data were determined by One-Way ANOVA [40]. Scheffe's post hoc test was used. Differences in distributions of categorical data were evaluated by Chi-square test $\left(\chi^{2}\right)$. The relationship between DR, obesity (defined by BMI), and risk factors was analyzed using Pearson's correlation test. Data were analyzed with IBM SPSS software version 12.0 [41]. In all the analyses, $P$ value of less than 0.01 and 0.05 were considered statistically significant.

\section{Results}

This study included 176 patients with type 1 diabetes (90 (51.1\%) males, and 86 (48.9\%) females) with a mean age of $40.03 \pm 14.66$ years. The mean age at onset was $21.70 \pm 13.05$ years and the mean duration of diabetes was $18.63 \pm 9.27$ years. According to the DR status, they were divided into three groups: group 1 (no retinopathy; $n=86$ ), group 2 (mild/moderate NPDR; $n=33$ ), group 3 (severe/very severe NPDR or PDR; $n=57)$. Incidence of any form of retinopathy in the examined patients $(n=176)$ was $51 \%$ of which $10.8 \%$ had severe to very severe NPDR and $21.6 \%$ had PDR.

Table 1 presents descriptive statistics of basic characteristics of type 1 diabetic patients divided into three groups according to DR status. There was no significant difference in gender between investigated groups. One-Way ANOVA was applied to compare means of age between the three observed groups ( $45.06 \pm 12.56$ years versus $37.19 \pm 16.62$ and $41.40 \pm$ 11.23 years; $P<0.05)$. Scheffe's post hoc test demonstrated only the significant difference between groups 1 and 2 with a test significance of $5 \%$.

Duration of diabetes was significantly different between the three groups $(23.03 \pm 8.94$ and $24.67 \pm 7.20$ years versus $12.94 \pm 6.77$ years; $P<0.01)$. Scheffe's post hoc test demonstrated the significant difference between groups 1 and 2 , as well as between groups 2 and 3 with a test significance of $1 \%$.

Table 2 presents descriptive statistics of metabolic and clinical parameters of type 1 diabetic patients divided into three groups according to their DR status. We observed a significant deterioration of $\mathrm{HbA}_{1} \mathrm{c}(P<0.01)$ and a significant increase in total cholesterol $(P<0.01)$ as well as systolic $(P<0.01)$ and diastolic blood pressure $(P<0.05)$ with the progression of retinopathy. Scheffe's post hoc test demonstrated the significant difference in mean $\mathrm{HbA}_{1} \mathrm{c}$ value between the groups 1 and 3 , as well as between the groups 2 and 3 and in mean total cholesterol value between the groups 1 and 3 with test significance of $1 \%$. The same test demonstrated the significant difference in mean systolic and diastolic blood pressure between the groups 1 and 3 with test significance of $1 \%$ for systolic and 5\% for diastolic blood pressure.

Patients with NPDR and PDR (groups 2 and 3, resp.) were more often treated with hypolipidemics $(P<0.01)$ and ACE-inhibitors $(P<0.01)$ than patients with no retinopathy (group 1); this was observed by Scheffe's post hoc test with test significance of $1 \%$. We also observed a significant increase in diabetic nephropathy $(P<0.01)$ with the progression of DR.

There was no significant difference in BMI between investigated groups (Table 3 ). In order to investigate the specific relationship between BMI and DR, patients were additionally divided according to their diabetic nephropathy status into two groups (with/without nephropathy). The group with nephropathy included the patients on dialysis due to diabetic nephropathy whilst the group without nephropathy consisted of patients with normoalbuminuria or microalbuminuria. In type 1 diabetic patients without nephropathy mean BMI was significantly different $(P<0.01)$ (Table 4$)$. Scheffe's post hoc testdemonstrated the significant difference in BMI between the groups 1 and 3 with test significance of 5\% (Table 5).

In type 1 diabetic patients with nephropathy, there was no significant difference in BMI between the groups divided according to the DR status (data not shown).

Body mass index was significantly positively correlated with $\mathrm{HbA}_{1} \mathrm{c}(r=0.156)$, total cholesterol $(r=0.256)$, triglycerides $(r=0.288)$, and systolic $(r=0.349)$ and diastolic blood pressure $(r=0.282)$, whereas significant negative correlations between BMI and HDL-cholesterol ( $r=$ $-0.155)$ as well as diabetic nephropathy $(r=-0.132)$ were observed. No correlation between BMI and diabetes duration $(r=0.136)$ was detected. These data are shown in Table 6.

DR was significantly positively correlated $(P=0.01)$ with diabetes duration $(r=0.524), \mathrm{HbA}_{1} \mathrm{c}(r=0.375)$, total cholesterol $(r=0.252)$, and systolic $(r=0.175)$ and diastolic blood pressure $(r=0.194)$ as well as diabetic nephropathy $(r=0.761)$. No correlations between diabetic retinopathy and BMI $(r=-0.053)$, triglycerides $(r=0.108)$, and HDLcholesterol ( $r=-0.029)$ were observed. These data are shown in Table 7.

In type 1 diabetic patients without nephropathy, DR was significantly positively correlated $(P=0.01)$ with BMI $(r=$ $0.247), \mathrm{HbA}_{1} \mathrm{c}(r=0.298)$, total cholesterol $(r=0.378)$, and systolic $(r=0.386)$ and diastolic blood pressure $(r=$ $0.302)$. In these patients, no correlations between diabetic retinopathy, triglycerides $(r=0.160)$, and HDL-cholesterol $(r=0.081)$, were seen. These data are shown in Table 8.

In type 1 diabetic patients on hemodialysis due to diabetic nephropathy, DR was significantly positively correlated only with $\mathrm{HbA}_{1} \mathrm{c}(r=0.499)$, while significant negative correlation between $\mathrm{DR}$ and $\operatorname{BMI}(r=-0.400)$ was detected. In these patients, no correlations between diabetic retinopathy 
TABLE 2: Metabolic and clinical parameters of type 1 diabetic patients $(n=176)$ divided into three groups according to diabetic retinopathy status.

\begin{tabular}{|c|c|c|c|c|}
\hline & $\begin{array}{l}\text { Group 1 } \\
(n=86)\end{array}$ & $\begin{array}{l}\text { Group } 2 \\
(n=33)\end{array}$ & $\begin{array}{l}\text { Group } 3 \\
(n=57)\end{array}$ & $P$ \\
\hline $\mathrm{HbA}_{1} \mathrm{c}(\%)^{*}$ & $7.25 \pm 1.56$ & $7.47 \pm 1.44$ & $8.56 \pm 1.32$ & $<0.01$ \\
\hline Total cholesterol $(\mathrm{mmol} / \mathrm{L})^{*}$ & $4.74 \pm 1.08$ & $5.18 \pm 1.01$ & $5.48 \pm 1.17$ & $<0.01$ \\
\hline Triglycerides $(\mathrm{mmol} / \mathrm{L})^{*}$ & $1.42 \pm 0.77$ & $1.41 \pm 0.81$ & $1.66 \pm 0.80$ & ns \\
\hline HDL-cholesterol $(\mathrm{mmol} / \mathrm{L})^{*}$ & $1.28 \pm 0.41$ & $1.35 \pm 0.36$ & $1.28 \pm 0.38$ & ns \\
\hline Insulin dosage $(\mathrm{IU} / \mathrm{kg})^{*}$ & $0.71 \pm 0.21$ & $0.77 \pm 0.16$ & $0.72 \pm 0.17$ & ns \\
\hline Systolic blood pressure $(\mathrm{mmHg})^{*}$ & $127.21 \pm 13.89$ & $135.76 \pm 20.75$ & $136.40 \pm 20.62$ & $<0.01$ \\
\hline Diastolic blood pressure $(\mathrm{mmHg})^{*}$ & $79.77 \pm 10.06$ & $81.82 \pm 9.03$ & $84.65 \pm 11.66$ & $<0.05$ \\
\hline Antihypertensive treatment ${ }^{* *}$ & 32.56 & 60.61 & 57.89 & $<0.01$ \\
\hline Hypolipidemic treatment ${ }^{* *}$ & 25.58 & 39.39 & 54.39 & $<0.01$ \\
\hline Nephropathy ${ }^{* *}$ & 5.81 & 24.24 & 78.95 & $<0.01$ \\
\hline
\end{tabular}

${ }^{*}$ mean $\pm \mathrm{SD}^{* *} \%$; percentage.

Group 1: no retinopathy, group 2: mild/moderate nonproliferative diabetic retinopathy; group 3: severe/very severe nonproliferative diabetic retinopathy or proliferative diabetic retinopathy; $\mathrm{HbA}_{1}$ c: glycated hemoglobin value; nephropathy: patients with type 1 diabetes on hemodialysis due to diabetic nephropathy.

TABLE 3: Body mass index (BMI) of type 1 diabetic patients $(n=176)$ divided into three groups according to diabetic retinopathy status.

\begin{tabular}{lcccc}
\hline & $\begin{array}{c}\text { Group 1 } \\
(n=86)\end{array}$ & $\begin{array}{c}\text { Group 2 } \\
(n=33)\end{array}$ & $\begin{array}{c}\text { Group 3 } \\
(n=57)\end{array}$ & $P$ \\
\hline BMI $\left(\mathrm{kg} / \mathrm{m}^{2}\right)^{*}$ & $24.06 \pm 3.48$ & $25.17 \pm 3.22$ & $24.43 \pm 4.28$ & $\mathrm{~ns}$ \\
\hline
\end{tabular}

${ }^{*}$ mean \pm SD.

Group 1: no retinopathy, group 2: mild/moderate nonproliferative diabetic retinopathy; group 3: severe/very severe nonproliferative diabetic retinopathy or proliferative diabetic retinopathy; BMI: body mass index.

TABLE 4: Body mass index (BMI) of type 1 diabetic patients $(n=124)$ without nephropathy divided into three groups according to diabetic retinopathy status.

\begin{tabular}{ccccc}
\hline $\begin{array}{c}\text { Group 1 } \\
(n=81)\end{array}$ & $\begin{array}{c}\text { Group 2 } \\
(n=25)\end{array}$ & $\begin{array}{c}\text { Group 3 } \\
(n=18)\end{array}$ & $P$ \\
\hline $\mathrm{BMI}\left(\mathrm{kg} / \mathrm{m}^{2}\right)^{*}$ & $24.03 \pm 3.52$ & $25.36 \pm 3.44$ & $26.93 \pm 3.24$ & $<0.01$ \\
\hline
\end{tabular}

${ }^{*}$ mean $\pm \mathrm{SD}$.

Group 1: no retinopathy, group 2: mild/moderate nonproliferative diabetic retinopathy; group 3: severe/very severe nonproliferative diabetic retinopathy or proliferative diabetic retinopathy; BMI: body mass index.

and total cholesterol $(P=-0.160)$, triglycerides $(r=-0.125)$, HDL-cholesterol $(r=-0.046)$, and systolic $(r=-0.049)$ and diastolic blood pressure $(r=-0.054)$ were observed. These data are shown in Table 9.

\section{Discussion}

Although type 1 accounts for only $5-10 \%$ of total cases of diabetes, it still represents a significant public health problem due to its rising incidence and prevalence as well as high risk of complications including retinopathy. The incidence of any stage of DR in patients with type 1 diabetes is higher than in type 2 and the advanced forms of DR with visual impairment and blindness usually develop throughout the patients most productive age [1-6]. According to the study, conducted to estimate the global prevalence of DR, age standardized prevalence of any form of DR in type 1 diabetic subjects aged $20-79$ years after 10 to 20 years of diabetes duration was $55.55 \%$ and $86.22 \%$ after more than 20 years. In the same study, the prevalence of PDR after 10 to 20 years was $19.46 \%$ and $40.36 \%$ after more than 20 years [42]. In our investigation, the mean duration of diabetes was $18.63 \pm$ 9.27 years with the prevalence of any form of retinopathy being $51 \%$ while $21.6 \%$ of patients had PDR. Furthermore, our results also confirm previous findings that the main risk factors for DR are diabetes duration, prolonged poor glycaemic control, hypertension, and high triglyceride levels $[7-10,15-17]$. We found significant differences depending on the duration of diabetes $(P<0.01)$ and the level of glycaemic control $(P<0.01)$ between investigated groups. Advanced stages of DR were present in patients with a longer duration of diabetes and higher values of $\mathrm{HbA}_{1} \mathrm{c}$. Additionally, a significant difference in the level of systolic $(P<0.01)$ and diastolic blood pressure $(P<0.05)$ as well as total triglyceride levels $(P<0.01)$ between the groups according to their DR status was found.

There are continuous efforts to correlate and explain the dynamic relationship between diabetic retinopathy and nephropathy, the two major microvascular complications of diabetes. Current data suggests that the presence of a preexisting retinopathy or nephropathy may contribute to the development of another, independent of established risk factors for microvascular complications especially in type 1 diabetic patients [43]. Our findings confirm the relationship between DR and nephropathy with obtained results indicating the existence of significant differences for the presence of nephropathy (patients on hemodialysis due to diabetic nephropathy) between the studied groups $(P<0.01)$. The strongest positive correlation of DR with investigated metabolic and clinical parameters was found for the presence 
TABLE 5: Scheffe's post-hoc test: dependent variable body mass index (BMI) of type 1 diabetic patients $(n=124)$ without nephropathy was divided into three groups according to diabetic retinopathy status.

\begin{tabular}{|c|c|c|c|c|c|c|}
\hline \multirow{2}{*}{ (I) diab. ret. } & \multirow{2}{*}{ (J) diab. ret. } & \multirow{2}{*}{ Mean difference (I-J) } & \multirow{2}{*}{ Std. error } & \multirow{2}{*}{ Sig. } & \multicolumn{2}{|c|}{ 95\% Confidence interval } \\
\hline & & & & & Lower bound & Upper bound \\
\hline \multirow{2}{*}{ Group 1} & Group 2 & -1.32886 & 0.75492 & 0.216 & -3.1985 & 0.5408 \\
\hline & Group 3 & $-2.89267^{*}$ & 0.89892 & 0.007 & -5.1190 & -0.6663 \\
\hline \multirow{2}{*}{ Group 2} & Group 1 & 1.32886 & 0.75492 & 0.216 & -0.5408 & 3.1985 \\
\hline & Group 3 & -1.56381 & 1.04668 & 0.331 & -4.1561 & 1.0285 \\
\hline \multirow{2}{*}{ Group 3} & Group 1 & $2.89267^{*}$ & 0.89892 & 0.007 & 0.6663 & 5.1190 \\
\hline & Group 2 & 1.56381 & 1.04668 & 0.331 & -1.0285 & 4.1561 \\
\hline
\end{tabular}

${ }^{*}$ The mean difference is significant at the 0.05 level.

TABLE 6: Correlation between body mass index and metabolic and clinical parameters in type 1 diabetic patients $(n=176)$.

\begin{tabular}{|c|c|}
\hline & $\begin{array}{c}\text { Body mass index (BMI) } \\
\text { Correlation test }^{*}\end{array}$ \\
\hline Diabetes duration (years) & 0.136 \\
\hline $\mathrm{HbA}_{1} \mathrm{c}(\%)$ & $0.156^{*}$ \\
\hline Total cholesterol (mmol/L) & $0.256^{* *}$ \\
\hline Triglycerides (mmol/L) & $0.288^{* *}$ \\
\hline HDL-cholesterol (mmol/L) & $-0.155^{* *}$ \\
\hline Systolic blood pressure (mmHg) & $0.349^{* *}$ \\
\hline Diastolic blood pressure $(\mathrm{mmHg})$ & $0.282^{* *}$ \\
\hline Nephropathy & -0.132 \\
\hline
\end{tabular}

TABLE 7: Correlation between diabetic retinopathy and diabetes duration, body mass index, and metabolic and clinical parameters in type 1 diabetic patients $(n=176)$.

\begin{tabular}{lc}
\hline & $\begin{array}{c}\text { Diabetic retinopathy } \\
\text { Correlation test }\end{array}$ \\
\hline Diabetes duration (years) & $0.524^{* *}$ \\
$\mathrm{BMI}\left(\mathrm{kg} / \mathrm{m}^{2}\right)$ & -0.053 \\
$\mathrm{HbA} \mathrm{c}(\%)$ & $0.375^{* *}$ \\
Total cholesterol (mmol/L) & $0.252^{* *}$ \\
Triglycerides $(\mathrm{mmol} / \mathrm{L})$ & 0.108 \\
HDL-cholesterol $(\mathrm{mmol} / \mathrm{L})$ & -0.029 \\
Systolic blood pressure $(\mathrm{mmHg})$ & $0.175^{*}$ \\
Diastolic blood pressure $(\mathrm{mmHg})$ & $0.194^{* *}$ \\
Nephropathy & $0.761^{* *}$ \\
\hline
\end{tabular}

${ }^{* *}$ Correlation is significant at the 0.01 level (2-tailed).

${ }^{*}$ Correlation is significant at the 0.05 level (2-tailed).

BMI: body mass index; $\mathrm{HbA}_{1} \mathrm{c}$ : glycated hemoglobin value; nephropathy: patients with type 1 diabetes on hemodialysis due to diabetic nephropathy.

of nephropathy $(r=0.761)$. DR was also significantly positively correlated with diabetes duration $(r=0.524)$, total cholesterol $(r=0.252), \mathrm{HbA}_{1} \mathrm{c}(r=0.375)$, systolic $(r=$ $0.175)$, and diastolic blood pressure $(r=0.194)$.
TABLE 8: Correlation between diabetic retinopathy and diabetes duration, body mass index, and metabolic and clinical parameters in type 1 diabetic patients without nephropathy $(n=124)$.

\begin{tabular}{lc}
\hline & $\begin{array}{c}\text { Diabetic retinopathy } \\
\text { Correlation test }\end{array}$ \\
\hline $\mathrm{BMI}\left(\mathrm{kg} / \mathrm{m}^{2}\right)$ & $0.247^{* *}$ \\
$\mathrm{HbA} \mathrm{c}(\%)$ & $0.298^{* *}$ \\
Total cholesterol $(\mathrm{mmol} / \mathrm{L})$ & $0.378^{* *}$ \\
Triglycerides $(\mathrm{mmol} / \mathrm{L})$ & 0.160 \\
HDL-cholesterol $(\mathrm{mmol} / \mathrm{L})$ & 0.081 \\
Systolic blood pressure $(\mathrm{mmHg})$ & $0.386^{* *}$ \\
Diastolic blood pressure $(\mathrm{mmHg})$ & $0.302^{* *}$ \\
\hline
\end{tabular}

** Correlation is significant at the 0.01 level (2-tailed).

${ }^{*}$ Correlation is significant at the 0.05 level (2-tailed).

BMI: body mass index; $\mathrm{HbA}_{1} \mathrm{c}$ : glycated hemoglobin value.

TABLE 9: Correlation between diabetic retinopathy and diabetes duration, body mass index, and metabolic and clinical parameters in type 1 diabetic patients with nephropathy $(n=52)$.

\begin{tabular}{lc}
\hline & $\begin{array}{c}\text { Diabetic retinopathy } \\
\text { Correlation test }\end{array}$ \\
\hline $\mathrm{BMI}\left(\mathrm{kg} / \mathrm{m}^{2}\right)$ & $-0.400^{* *}$ \\
$\mathrm{HbA} \mathrm{A}_{1} \mathrm{c}(\%)$ & $0.499^{* *}$ \\
Total cholesterol $(\mathrm{mmol} / \mathrm{L})$ & -0.160 \\
Triglycerides $(\mathrm{mmol} / \mathrm{L})$ & -0.125 \\
$\mathrm{HDL}-\mathrm{cholesterol}(\mathrm{mmol} / \mathrm{L})$ & -0.046 \\
Systolic blood pressure $(\mathrm{mmHg})$ & -0.049 \\
Diastolic blood pressure $(\mathrm{mmHg})$ & -0.054 \\
\hline${ }^{* *}$ Correlation is significant at the 0.01 level $\left(2\right.$-tailed). ${ }^{*}$ Correlation is \\
significant at the 0.05 level $(2$-tailed). \\
BMI: body mass index; $\mathrm{HbA} \mathrm{A}_{1} \mathrm{c}$ : glycated hemoglobin value.
\end{tabular}

Since current treatment options [7-10, 15-17, 44, 45] fail to entirely eliminate the risk of microvascular diabetic complications, there is a continuing need for the development of new management strategies. Increasing interest is addressed to modifiable risk factors particularly obesity due to its rising incidence and established association with diabetes. To date, the relationship between BMI and DR has been examined in a number of epidemiologic studies giving conflicting results [20-33]. This inconsistency may be partly explained 
by methodological differences, diversity in study participants, lack of comprehensive anthropometric measurements, inadequate clinical sample size, and particularly racial or ethnic differences $[31,32]$.

Although several biological theories are proposed, the exact pathophysiological mechanisms supporting the relationship between higher BMI and DR are not entirely clear. Metabolic syndrome, increased oxidative stress, and inflammation due to their association with both obesity and DR have been implied as possible connecting pathogenic mechanisms $[8,14,20,46]$. Likewise, growing attention has been directed towards the role of vasoproliferative factors in the pathogenesis of DR, whereby their concentrations have been found to be higher in the vitreous of eyes with PDR $[47,48]$. Similarly in the serum of obese individuals elevated angiogenic factors have been detected providing additional evidence of the possible bond between obesity and PDR [46, 49]. Obesity and type 1 diabetes are widespread dysmetabolic disorders whose long term complications include severe impairment of the vascular system [50-52]. Several studies have suggested that weight gain may also be involved in the onset as well as long-term progression of type 1 diabetes and may contribute to its rising incidence as confirmed in type $2[51,53]$. Type 1 diabetes is an inflammatory disease in which its very onset is caused by an inflammatory reaction via lymphocyte-mediated destruction of pancreatic beta cells. This is further followed by a chronic state of low-intense body inflammation episodically aggravated by hyperglycemic fluctuations. Obesity is also a disorder associated with elevated inflammation, oxidative stress, and insulin resistance with growing evidence suggesting that an interrelationship with diabetes could include these mechanisms [52-54]. Epidemiological data have identified hyperlipidemia and hypertension to be connected with obesity as risk factors for DR $[28,50]$. In fact, metabolic syndrome encompassing these conditions has also been shown to be associated with retinopathy [55] where many overweight type 1 diabetic patients are difficult to treat and require a relatively high dose of insulin to achieve adequate glycemic control $[55,56]$. It is possible that metabolic syndrome and its associated insulin resistance although usually associated with type 2 diabetes may also be a clinical feature for some type 1 diabetic patients [56]. Endothelial dysfunction (ED) as an early indicator of DR is also present in obesity and is characterised by increased levels of adhesion molecules. ED caused by oxidative stress and inflammation processes both connected to diabetes and obesity plays a significant role in the pathogenesis of diabetic arterial wall damage [57-59].

It is generally established that in obese and diabetic individuals, inflammatory and oxidative processes are found to be consistently elevated. The level of inflammatory activation seems to be proportional to severity of obesity in overweight individuals and the quality of glycemic control in type 1 diabetic patients, respectively. Obesity increases the prevalence of several risk factors known to be involved in DR onset and development including inflammatory markers. According to newer concepts, adipose tissue is an active endocrine proinflammatory organ that secretes a large number of bioactive molecules, named adipokines, such as interleukin-6 (IL-6), tumour necrosis factor- $\alpha$ (TNF- $\alpha$ ) leptin, and adiponectin. They regulate body weight homeostasis, influence coagulation, lipid levels, inflammation, oxidative stress, and insulin resistance as well as atherosclerosis and diabetes occurrence. Plasma leptin levels which are elevated in obese individuals and which correlate positively with BMI and insulin resistance $[60,61]$ have also been related to hypertensive and diabetic retinopathy [61]. Recent findings show that leptin promotes vascular endothelial cell proliferation and angiogenesis in vitro and neovascularisation in vivo [60]. Conversely, adiponectin levels correlate negatively with visceral and subcutaneous fat areas $[62,63]$ with low adiponectin levels associated with obesity, type 2 diabetes, and insulin resistance [59]. An increased level of adiponectin was found in diabetic and nondiabetic subjects with impaired kidney function as well as in type 1 diabetic patients without complications and particularly in those with diabetic nephropathy [62-65]. In our study, there were no statistically significant differences in BMI between, the investigated groups according to DR status. However, after excluding patients with nephropathy, BMI was significantly higher in those with advanced stages of DR $(P<0.01)$. Moreover, in patients without nephropathy, a statistically positive correlation between DR and BMI was found $(r=$ $0.247 ; P<0.01)$ whilst in patients with nephropathy, this correlation was negative $(r=-0.400 ; P<0.01)$.

These obtained findings may be connected to adipokines particularly adiponectin and may be the result of the contradictory effect of obesity and impaired renal function on adiponectin levels [53]. Adiponectin is conversely correlated with BMI, and since kidney dysfunction increases its levels in obese diabetic patients with nephropathy, this mutual influence may have a nullifying effect. In patients without nephropathy, a potential action of adiponectin can be linked to obesity and its impact on oxidative stress and inflammatory markers and therefore DR development may be more pronounced.

Our study has shown that BMI in correlation with poor glycaemic control, hypertension, and dyslipidemia appears to be associated with the progression of DR in type 1 diabetic patients without nephropathy. Several findings indicate the existence of mutual pathogenic mechanisms including inflammation, oxidative stress, and endothelial dysfunction between retinopathy and nephropathy. However, it is not entirely clear in what phase of those complications specific mechanisms dominate or at what stage and to what extent they overlap. Moreover, it is questionable whether these pathogenetic mechanisms impact differently on distinct stages of retinopathy or nephropathy development, whereby a slight modification in action of just one bioactive molecule may cause an entirely different consequential outcome. This is of particular relevance since in chronic kidney disease due to impaired renal biodegradation and elimination, various active protein levels may be increased. Further, it is well established that ED correlates with the progression of renal disorder where it is inactive at the very beginning of the disease yet has an active role in the progression of the glomerulosclerosis causing nephropathy deterioration [66]. Likewise in patients with DR without nephropathy, it is 
possible that endothelial lesions and dysfunction have less expressed or no influence on retinopathy development.

Obtained results illustrate the value of obesity assessment as a possible modifiable risk factor which may consequently have potential clinical implications on the management of DR. A possible limitation of our study may stem from the cross-sectional design itself in which accurate determination of observed correlation findings may be limited. It would therefore be advantageous to present the course of change in BMI as a very dynamic parameter over time by conducting a prospective study addressing this specific question. Findings showing that BMI is associated with the presence and severity of DR in patients without nephropathy open up implications for further research and intervention in order to elucidate the role of oxidative stress, inflammation, body weight change, and their interaction in the pathogenesis of DR particularly relating to nephropathy. In patients with DR and without nephropathy, the obtained results may also have clinical implications since in these patients, a tight regulation of body weight managed by lifestyle intervention is highly advisable. In this case, alongside glycaemic, hypertension, and lipid control, we may have an additional changeable risk factor which could influence DR development and onset itself. A better and more detailed understanding of all the facets linking obesity and diabetes with the components of the underlying inflammatory and oxidative dysregulation represents the source of future ability for the successful prevention and management of DR.

\section{Conflict of Interests}

There is no conflict of interests regarding the publication of this paper.

\section{References}

[1] L. Y. Melendez-Ramirez, R. J. Richards, and W. T. Cefalu, "Complications of type 1 diabetes," Endocrinology and Metabolism Clinics of North America, vol. 39, no. 3, pp. 625-640, 2010.

[2] American Diabetes Association, "Diagnosis and classification of diabetes mellitus," Diabetes Care, vol. 32, supplement 1, pp. S62-S67, 2009.

[3] D. M. Maahs, N. A. West, J. M. Lawrence, and E. J. MayerDavis, "Epidemiology of type 1 diabetes," Endocrinology and Metabolism Clinics of North America, vol. 39, no. 3, pp. 481-497, 2010.

[4] G. P. Forlenza and M. Rewers, "The epidemic of type 1 diabetes: what is it telling us?" Current Opinion in Endocrinology, Diabetes and Obesity, vol. 18, no. 4, pp. 248-251, 2011.

[5] J. E. Shaw, R. A. Sicree, and P. Z. Zimmet, "Global estimates of the prevalence of diabetes for 2010 and 2030," Diabetes Research and Clinical Practice, vol. 87, no. 1, pp. 4-14, 2010.

[6] G. Roglic, N. Unwin, P. H. Bennett et al., "The burden of mortality attributable to diabetes: realistic estimates for the year 2000," Diabetes Care, vol. 28, no. 9, pp. 2130-2135, 2005.

[7] S. E. Moss, R. Klein, and B. E. K. Klein, "The 14-year incidence of visual loss in a diabetic population," Ophthalmology, vol. 105, no. 6, pp. 998-1003, 1998.

[8] L. M. Aiello, "Perspectives on diabetic retinopathy," American Journal of Ophthalmology, vol. 136, no. 1, pp. 122-135, 2003.
[9] Diabetes Control and Diabetes Control and Complication Trial / Epidemiology of Diabetes Interventions and Complications Research Group, "Retinopathy and nephropathy in patients with type 1 diabetes four years after a trial of intensive therapy," The New England Journal of Medicine, vol. 342, no. 6, pp. 381$389,2000$.

[10] I. M. Stratton, E. M. Kohner, S. J. Aldington et al., "UKPDS 50: risk factors for incidence and progression of retinopathy in type II diabetes over 6 years from diagnosis," Diabetologia, vol. 44, no. 2, pp. 156-163, 2001.

[11] S. Kaštelan, M. Tomić, J. Pavan, and S. Orešković, "Maternal immune system adaptation to pregnancy — a potential influence on the course of diabetic retinopathy," Reproductive Biology and Endocrinology, vol. 8, article 124, 2010.

[12] S. Kaštelan, M. Tomić, J. Salopek-Rabatić et al., "The association between the HLA system and retinopathy development in patients with type 1 diabetes mellitus," Collegium Antropologicum, vol. 37, supplement 1, pp. 65-70, 2013.

[13] M. D. Davis, "Diabetic retinopathy: a clinical overview," Diabetes Care, vol. 15, no. 12, pp. 1844-1874, 1992.

[14] M. Tomić, S. Ljubić, S. Kaštelan, A. Gverović Antunica, A. Jazbec, and T. Poljičanin, "Inflammation, haemostatic disturbance and obesity: possible link to pathogenesis of diabetic retinopathy in type 2 diabetes," Mediators in Inflammation, vol. 2013, Article ID 818671, 10 pages, 2013.

[15] The Diabetes Control and Complications Trial Research Group, "The effect of intensive treatment of diabetes on the development and progression of long-term complications in insulindependent diabetes mellitus," The New England Journal of Medicine, vol. 329, no. 14, pp. 977-986, 1993.

[16] A. K. Sjolie, J. Stephenson, S. Aldington et al., "Retinopathy and vision loss in insulin-dependent diabetes in Europe: The EURODIAB IDDM Complications Study," Ophthalmology, vol. 104, no. 2, pp. 252-260, 1997.

[17] B. Karamanos, M. Porta, M. Songini et al., "Different risk factors of microangiopathy in patients with type I diabetes mellitus of short versus long duration. The EURODIAB IDDM Complications Study," Diabetologia, vol. 43, no. 3, pp. 348-355, 2000.

[18] J. W. J. Beulens, A. Patel, J. R. Vingerling et al., "Effects of blood pressure lowering and intensive glucose control on the incidence and progression of retinopathy in patients with type 2 diabetes mellitus: a randomised controlled trial," Diabetologia, vol. 52, no. 10, pp. 2027-2036, 2009.

[19] F. Ismail-Beigi, T. Craven, M. A. Banerji et al., "Effect of intensive treatment of hyperglycaemia on microvascular outcomes in type 2 diabetes: an analysis of the ACCORD randomised trial," The Lancet, vol. 376, no. 9739, pp. 419-430, 2010.

[20] S. Kaštelan, M. Tomić, A. Gverović Antunica, S. Ljubić, J. Salopek-Rabatić, and M. Karabatić, "Body mass index-a risk factor for retinopathy in type 2 diabetic patients," Mediators of Inflammation, vol. 2013, Article ID 436329, 8 pages, 2013.

[21] N. Chaturvedi, J. H. Fuller, R. J. Jarrett et al., "Mortality risk by body weight and weight change in people with NIDDM: The WHO Multinational Study of Vascular Disease in Diabetes," Diabetes Care, vol. 18, no. 6, pp. 766-774, 1995.

[22] M. Henricsson, L. Nyström, G. Blohmé et al., “The incidence of retinopathy 10 years after diagnosis in young adult people with diabetes: results from the nationwide population-based Diabetes Incidence Study in Sweden (DISS)," Diabetes Care, vol. 26, no. 2, pp. 349-354, 2003. 
[23] UK Prospective Diabetes Study (UKPDS) Group, "Effect of intensive blood-glucose control with metformin on complications in overweight patients with type 2 diabetes (UKPDS 34)," The Lancet, vol. 352, no. 9131, pp. 854-865, 1998.

[24] H. A. van Leiden, J. M. Dekker, A. C. Moll et al., "Risk factors for incident retinopathy in a diabetic and nondiabetic population: The Hoorn Study," Archives of Ophthalmology, vol. 121, no. 2, pp. 245-251, 2003.

[25] M. Dirani, J. Xie, E. Fenwick et al., "Are obesity and anthropometry risk factors for diabetic retinopathy? The diabetes management project," Investigative Ophthalmology \& Visual Science, vol. 52, no. 7, pp. 4416-4421, 2011.

[26] L. Zhang, G. Krzentowski, A. Albert, and P. J. Lefebvre, "Risk of developing retinopathy in diabetes control and complications trial type 1 diabetic patients with good or poor metabolic control," Diabetes Care, vol. 24, no. 7, pp. 1275-1279, 2001.

[27] X. Li and Z. Wang, "Prevalence and incidence of retinopathy in elderly diabetic patients receiving early diagnosis and treatment," Experimental and Therapeutic Medicine, vol. 5, no. 5, pp. 1393-1396, 2013.

[28] C. E. M. De Block, I. H. De Leeuw, and L. F. Van Gaal, "Impact of overweight on chronic microvascular complications in type 1 diabetic patients," Diabetes Care, vol. 28, no. 7, pp. 1649-1655, 2005.

[29] R. Klein, B. E. K. Klein, and S. E. Moss, "Is obesity related to microvascular and macrovascular complications in diabetes? The Wisconsin Epidemiologic Study of Diabetic Retinopathy," Archives of Internal Medicine, vol. 157, no. 6, pp. 650-656, 1997.

[30] R. Klein, B. E. Klein, S. E. Moss, M. D. Davis, and D. L. DeMets, "The Wisconsin Epidemiologic Study of Diabetic Retinopathy. III. Prevalence and risk of diabetic retinopathy when age at diagnosis is 30 or more years," Archives of Ophthalmology, vol. 102, no. 4, pp. 527-532, 1984.

[31] L. S. Lim, E. Shyong Tai, P. Mitchell et al., "C-reactive protein, body mass index, and diabetic retinopathy," Investigative Ophthalmology and Visual Science, vol. 51, no. 9, pp. 4458-4463, 2010.

[32] R. Raman, P. K. Rani, P. Gnanamoorthy, R. R. Sudhir, G. Kumaramanikavel, and T. Sharma, "Association of obesity with diabetic retinopathy: sankara nethralaya diabetic retinopathy epidemiology and molecular genetics study (SN-DREAMS Report no. 8)," Acta Diabetologica, vol. 47, no. 3, pp. 209-215, 2010.

[33] G. K. Dowse, A. R. G. Humphrey, V. R. Collins et al., "Prevalence and risk factors for diabetic retinopathy in the multiethnic population of Mauritius," American Journal of Epidemiology, vol. 147, no. 5, pp. 448-457, 1998.

[34] M. Vučić Lovrenčić and E. Topić, "Hemoglobin Alc: standardizacija 'zlatnog standarda"' Biochemia Medica, vol. 16, no. 1, pp. 25-36, 2006.

[35] P. N. M. Demacker, G. J. M. Boerma, and H. Baadenhuijsen, "Evaluation of accuracy of 20 different test kits for the enzymic determination of cholesterol," Clinical Chemistry, vol. 29, no. 11, pp. 1916-1922, 1983.

[36] M. W. McGowan, J. D. Artiss, D. R. Strandbergh, and B. Zak, "A peroxidase-coupled method for the colorimetric determination of serum triglycerides," Clinical Chemistry, vol. 29, no. 3, pp. 538-542, 1983.

[37] S. K. Kumanyika, E. Obarzanek, N. Stettler et al., "Populationbased prevention of obesity: the need for comprehensive promotion of healthful eating, physical activity, and energy balance: a scientific statement from American Heart Association
Council on Epidemiology and Prevention, Interdisciplinary Committee for prevention (formerly the expert panel on population and prevention science)," Circulation, vol. 118, no. 4, pp. 428-464, 2008.

[38] S. J. Aldington, E. M. Kohner, S. Meuer, R. Klein, and A. K. Sjolie, "Methodology for retinal photography and assessment of diabetic retinography: The EURODIAB IDDM Complications Study," Diabetologia, vol. 38, no. 4, pp. 437-444, 1995.

[39] KDOQI, "KDOQI clinical practice guidelines and clinical practice recommendations for diabetes and chronic kidney disease," American Journal of Kidney Diseases, vol. 49, supplement 2, no. 2, pp. S12-S154, 2007.

[40] R. R. Sokal and F. J. Rohlf, Biometry: The Principles and Practice of Statistics in Biological Researchedition, W. H. Freeman, New York, NY, USA, 3rd edition, 1995.

[41] StatSoft, Electronic Statistics Textbook, StatSoft, Tulsa, Okla, USA, 2011, http://www.statsoft.com/Textbook.

[42] J. W. Y. Yau, S. L. Rogers, R. Kawasaki et al., "Global prevalence and major risk factors of diabetic retinopathy," Diabetes Care, vol. 35, no. 3, pp. 556-564, 2012.

[43] P. Romero-Aroca, M. Baget-Bernaldiz, J. Reyes-Torres et al., "Relationship between diabetic retinopathy, microalbuminuria and overt nephropathy, and twenty-year incidence follow-up of a sample of type 1 diabetic patients," Journal of Diabetes and Its Complications, vol. 26, no. 6, pp. 506-512, 2012.

[44] The Diabetes Control and Complications Trial Research Group, "The effect of intensive treatment of diabetes on the development and progression of long-term complications in insulindependent diabetes mellitus," The New England Journal of Medicine, vol. 329, no. 14, pp. 977-986, 1993.

[45] P. Reichard, B.-Y. Nilsson, and U. Rosenqvist, "The effect of long-term intensified insulin treatment on the development of microvascular complications of diabetes mellitus," The New England Journal of Medicine, vol. 329, no. 5, pp. 304-309, 1993.

[46] J. V. Silha, M. Krsek, P. Sucharda, and L. J. Murphy, "Angiogenic factors are elevated in overweight and obese individuals," International Journal of Obesity, vol. 29, no. 11, pp. 1308-1314, 2005.

[47] L. P. Aiello, R. L. Avery, P. G. Arrigg et al., "Vascular endothelial growth factor in ocular fluid of patients with diabetic retinopathy and other retinal disorders," The New England Journal of Medicine, vol. 331, no. 22, pp. 1480-1487, 1994.

[48] A. Praidou, S. Androudi, P. Brazitikos, G. Karakiulakis, E. Papakonstantinou, and S. Dimitrakos, "Angiogenic growth factors and their inhibitors in diabetic retinopathy," Current Diabetes Reviews, vol. 6, no. 5, pp. 304-312, 2010.

[49] S. Miyazawa-Hoshimoto, K. Takahashi, H. Bujo, N. Hashimoto, and Y. Saito, "Elevated serum vascular endothelial growth factor is associated with visceral fat accumulation in human obese subjects," Diabetologia, vol. 46, no. 11, pp. 1483-1488, 2003.

[50] D. W. Haslam and W. P. T. James, "Obesity," The Lancet, vol. 366, no. 9492, pp. 1197-1209, 2005.

[51] I. M. Libman, M. Pietropaolo, S. A. Arslanian, R. E. LaPorte, and D. J. Becker, "Changing prevalence of overweight children and adolescents at onset of insulin-treated diabetes," Diabetes Care, vol. 26, no. 10, pp. 2871-2875, 2003.

[52] B. Tran, S. Oliver, J. Rosa, and P. Galassetti, "Aspects of inflammation and oxidative stress in pediatric obesity and type 1 diabetes: an overview of ten years of studies," Experimental Diabetes Research, vol. 2012, Article ID 683680, 7 pages, 2012. 
[53] G. L. King, "The role of inflammatory cytokines in diabetes and its complications," Journal of Periodontology, vol. 79, no. 8, pp. 1527-1534, 2008.

[54] J. F. Keaney Jr., M. G. Larson, R. S. Vasan et al., "Obesity and systemic oxidative stress: clinical correlates of oxidative stress in the Framingham study," Arteriosclerosis, Thrombosis, and Vascular Biology, vol. 23, no. 3, pp. 434-439, 2003.

[55] T. Y. Wong, B. B. Duncan, S. H. Golden et al., "Associations between the metabolic syndrome and retinal microvascular signs: the atherosclerosis risk in communities study," Investigative Ophthalmology and Visual Science, vol. 45, no. 9, pp. 29492954, 2004.

[56] M. McGill, L. Molyneaux, S. M. Twigg, and D. K. Yue, “The metabolic syndrome in type 1 diabetes: does it exist and does it matter?" Journal of Diabetes and Its Complications, vol. 22, no. 1, pp. 18-23, 2008.

[57] L. F. Van Gaal, I. L. Mertens, and C. E. De Block, "Mechanisms linking obesity with cardiovascular disease," Nature, vol. 444, no. 7121, pp. 875-880, 2006.

[58] G. De Mattia, M. C. Bravi, O. Laurenti et al., "Endothelial dysfunction and oxidative stress in type 1 and type 2 diabetic patients without clinical macrovascular complications," Diabetes Research and Clinical Practice, vol. 79, no. 2, pp. 337-342, 2008.

[59] E. Fuentes, F. Fuentes, G. Vilahur, L. Badimon, and I. Palomo, "Mechanisms of chronic state of inflammation as mediators that link obese adipose tissue and metabolic syndrome," Mediators of Inflammation, vol. 2013, Article ID 136584, 11 pages, 2013.

[60] M. R. Sierra-Honigmann, A. K. Nath, C. Murakami et al., "Biological action of leptin as an angiogenic factor," Science, vol. 281, no. 5383, pp. 1683-1686, 1998.

[61] G. Uckaya, M. Ozata, Z. Bayraktar, V. Erten, N. Bingol, and I. C. Ozdemir, "Is leptin associated with diabetic retinopathy?" Diabetes Care, vol. 23, no. 3, pp. 371-376, 2000.

[62] M. Matsuda, F. Kawasaki, K. Yamada et al., "Impact of adiposity and plasma adipocytokines on diabetic angiopathies in Japanese type 2 diabetic subjects," Diabetic Medicine, vol. 21, no. 8, pp. 881-888, 2004.

[63] M. Tomić, S. Ljubić, and S. Kaštelan, “The role of inflammation and endothelial dysfunction in the pathogenesis of diabetic retinopathy," Collegium Antropologicum, vol. 37, supplement 1, pp. 51-57, 2013.

[64] A. P. Doumatey, J. Zhou, H. Huang et al., "Circulating adiponectin is associated with renal function independent of age and serum lipids in west Africans," Internal Journal of Nephrology, vol. 2012, Article ID 730920, 8 pages, 2012.

[65] N. M. Habeeb, O. I. Youssef, A. A. Saab, and E. S. El Hadidi, "Adiponectin as a marker of complications in type I diabetes," Indian Pediatrics, vol. 49, no. 4, pp. 277-280, 2012.

[66] A. S. Astrup, L. Tarnow, L. Pietraszek et al., "Markers of endothelial dysfunction and inflammation in type 1 diabetic patients with or without diabetic nephropathy followed for 10 years: association with mortality and decline of glomerular filtration rate," Diabetes Care, vol. 31, no. 6, pp. 1170-1176, 2008. 


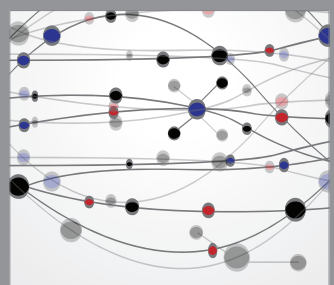

The Scientific World Journal
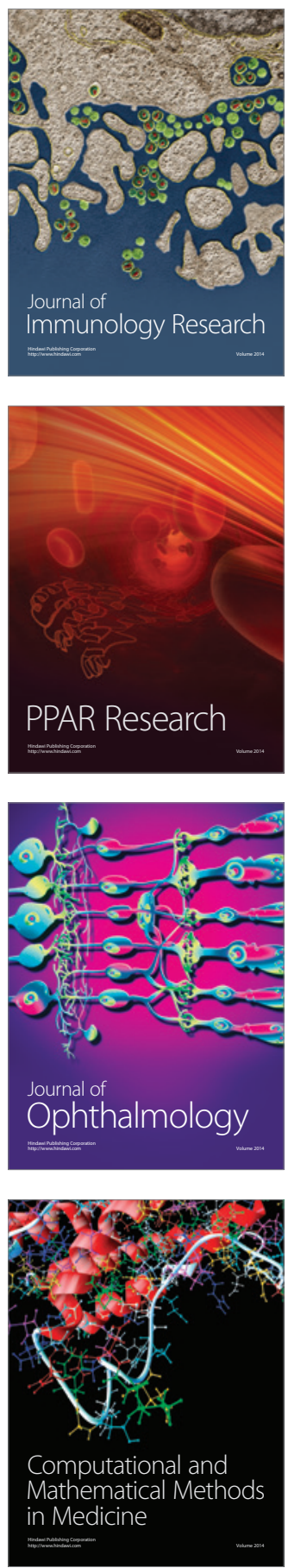

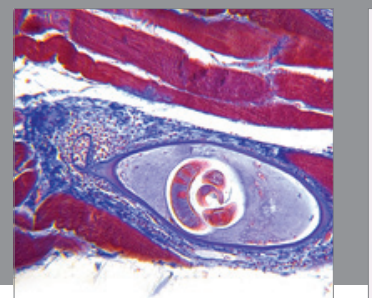

Gastroenterology

Research and Practice
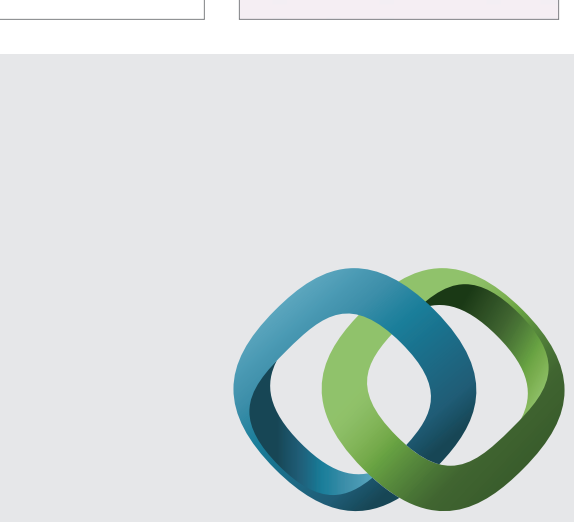

\section{Hindawi}

Submit your manuscripts at

http://www.hindawi.com
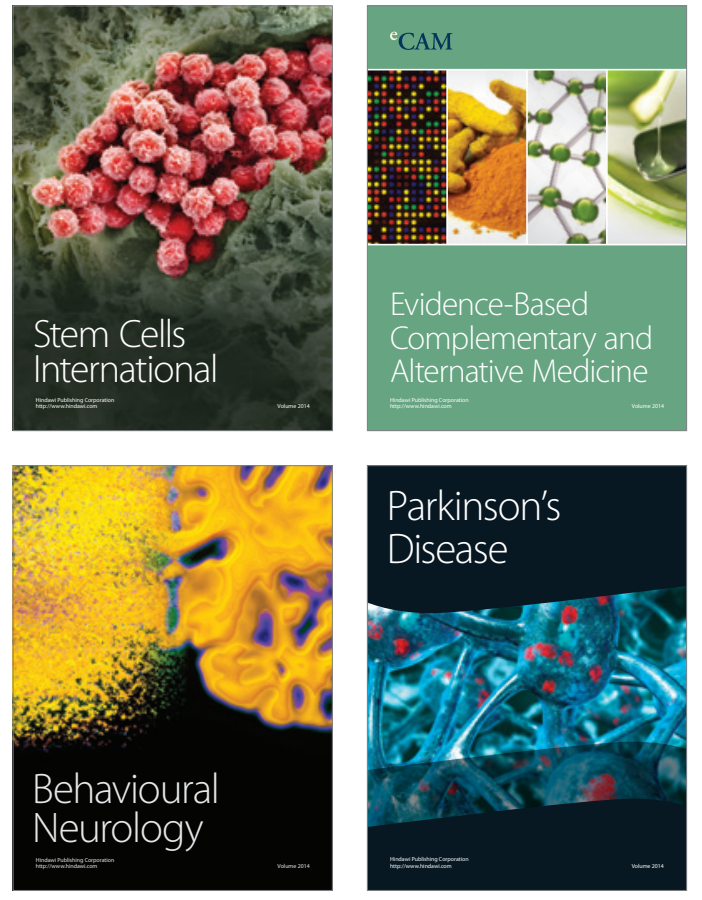
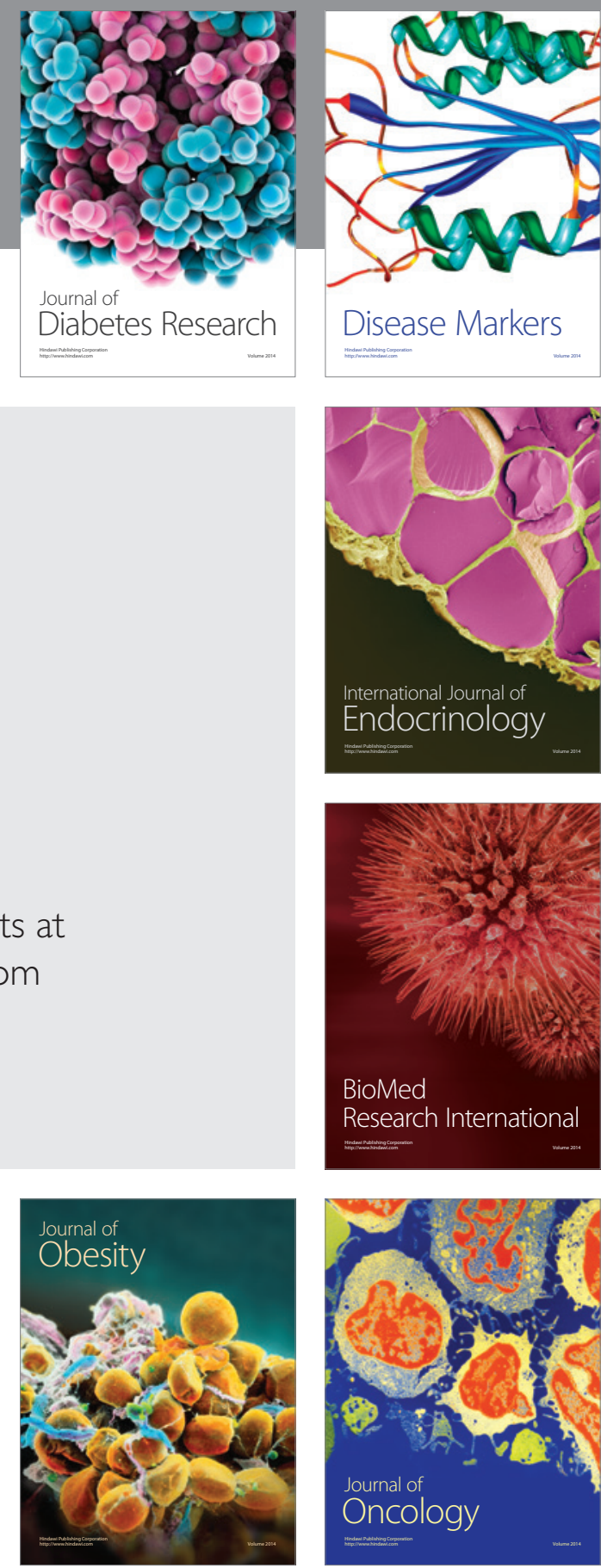

Disease Markers
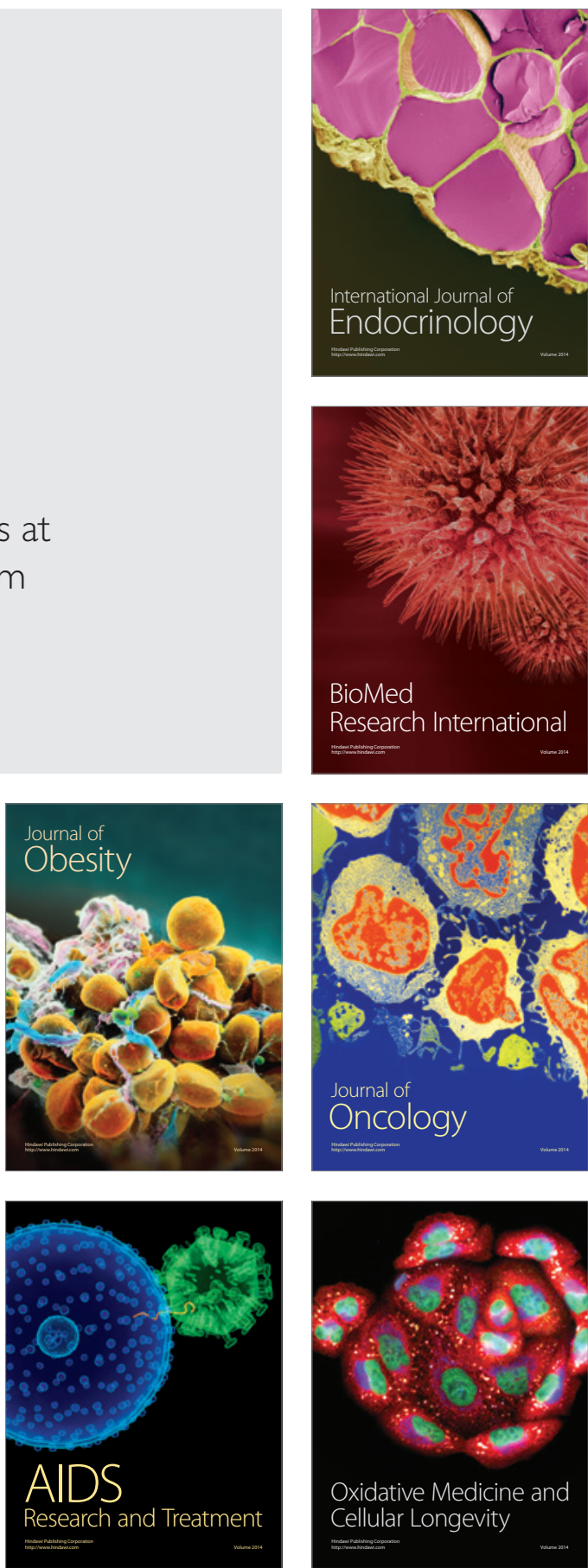